\title{
MIR19B1 Pre- miRNA
}

National Cancer Institute

\section{Source}

National Cancer Institute. MIR19B1 Pre- miRNA. NCI Thesaurus. Code C82709.

MIR19B1 pre-miRNA is an oligoribonucleotide that is encoded by the human MIR19B1 gene and is involved in the regulation of gene expression. 